\title{
Looking for an answer under the shadow-Life narratives among people living with HIV/AIDS and their caregivers
}

\author{
Shou-Yu Cindy Wang ${ }^{1}$, Mei-Li Chang*2, Ying-Ying Chang ${ }^{3}$ \\ ${ }^{1}$ Discipline of Nursing, School of Health, University of New England, Australia \\ ${ }^{2}$ Department of Nursing, Wuri Lin Shin Hospital, Taichung City, Taiwan \\ ${ }^{3}$ Department of Nursing, Taichung Veterans General Hospital, Puli Branch, Taiwan
}

Received: January 5, 2021

DOI: $10.5430 /$ jnep.v11n8p11
Accepted: March 14, 2021

Online Published: March 30, 2021

\begin{abstract}
In Taiwan, the number of cases of newly diagnosed AIDS is increasing every year, and those diagnosed tend to be younger people. Antiretroviral therapy has increased the overall survival rate; however, people living with AIDS face many problems in adapting to this lifelong illness. In this study, we investigate the life narrative and interactions of people living with AIDS and their caregivers. Using a narrative approach, 12 participants, consisting AIDS patients and their caregivers, were invited to one-on-one in-depth interviews to explore their life experience. The study's results identified five themes: an inability to speak to others about AIDS, isolating oneself from the world, promises that cannot be given, condemnation from others for having AIDS, and having an unknown future. The stories were based on these five themes. Understanding the life narratives of those with AIDS can help to address and resolve the problems associated with living with AIDS. When medical science and technology are advancing, the Internet, media, and other more directed education have enabled easy acquisition of AIDS-related knowledge. AIDS has become a chronic disease. However, the public still cannot accept AIDS. People living with AIDS and their caregivers have not been able to walk out of the shadow of the disease, as even for those who are willing to reveal their illness, the results do not always turn out well. People living with AIDS and their caregivers can only secretly take care of and encourage each other.
\end{abstract}

Key Words: People living with AIDS, Caregiver, Stigma, Narrative, Qualitative research

\section{INTRODUCTION}

According to the World Health Organization (WHO) and the Joint United Nations Program on AIDS (UNAIDS), the number of people infected with the human immunodeficiency virus (HIV) worldwide had reached 38.0 million by the end of 2019, with Africa having the highest number at 25.84 million. ${ }^{[1]}$ The number of newly diagnosed patients was 0.99 million in Africa, accounting for 58\% of the total global increase. In 2019, 5.8 million people were infected in the Asia-Pacific region, accounting for $15 \%$ of the total number of people living with AIDS worldwide. ${ }^{[2]}$ The prevalence of AIDS among adults aged 15-49 years worldwide was estimated to be $0.7 \%$, approximately 1 in 25 adults was HIVpositive, ${ }^{[3]}$ and the number of deaths due to AIDS worldwide was 0.69 million. ${ }^{[4]}$

In Taiwan, the first patient diagnosed with HIV was reported

\footnotetext{
*Correspondence: Mei-Li Chang; Email: meili600122@ gmail.com; Address: No. 25, Ln. 713, Sec. 1, Jiahou Rd., Houli Dist., Taichung City 421, Taiwan (R.O.C.).
} 
in 1984. From then until 28 February 2021, 41,222 people were diagnosed with HIV, of which 39,083 were men. ${ }^{[5]}$ Most people living with AIDS are young adults. According to the AIDS statistics of the Centers for Disease Control (CDC), in 2020, 92.31\% of newly reported HIV infections were in people aged between 15 and 49 years. ${ }^{[5]}$ The risk factors for HIV infection reveal sexual behavior to be the primary transmission route, with male homosexual behavior dominating, accounting for $82.03 \%$, followed by heterosexual behavior, accounting for $10.78 \%$, while the proportion accounted for by injecting of drugs was only $1.58 \% .^{[5]}$

In the United States, an increasing number of people living with AIDS are entering old age, and numerous people living with AIDS are middle-aged women over the age of 50 years; they are often ostracized if they disclose that they have the disease. ${ }^{[6]}$ Older people are concerned about the stigma of the disease, their well-being, their age-related AIDS comorbidities, self-care, family support, and access to medical resources. ${ }^{[7]}$ In addition, internal stigma affects quality of care, quality of life, and public health. More serious internal stigma leads to higher AIDS-related mortality. ${ }^{[8]}$

Studies in Africa have found that people living with AIDS are stigmatized both externally and internally to themselves and other people, leading to disease deterioration, physical and mental problems, unemployment, poverty, dependence on people, and destruction of interpersonal relationships. Their coping strategies are emotional support from other people living with AIDS and religion. ${ }^{[9]}$ Because of the stigma of the disease and the chronic course of AIDS, caregivers of people living with AIDS also often face significant pressure during the care process, and religion can play a crucial role in the caregivers' lives. ${ }^{[10]}$

In Saudi Arabia, the concerns of people living with AIDS include disease notification, stigma, religious beliefs, fear, vulnerability, and lack of psychosocial support. ${ }^{[11]}$ Religious spirituality is the primary coping response of people to the fear of punishment from God, their future, and death. ${ }^{[11]}$ Research in the Philippines has shown that improving the knowledge of people living with AIDS regarding the disease can prolong their lifespan and help them actively face the disease. ${ }^{[12]}$ A Japanese study indicated that not all participants can accept their diagnosis of AIDS; furthermore, the study found that the stigma associated with AIDS in Japan is similar to that in other Asian countries. ${ }^{[13]}$

According to a Malaysian study, $75 \%$ of family caregivers of people living with AIDS are women. ${ }^{[14]}$ They must ensure that the person under their care complies with his or her medicine regime, and they must also face the other family members and take responsibility for the care of the person living with AIDS. In many cases, caregivers are also unable to maintain a household income due to the confidentiality measures taken for the benefit of the care receiver, resulting in financial difficulties. ${ }^{[14]}$

Research studies undertaken in Taiwan have found that people living with AIDS are often prone to depression because of changes in the disease process. In particular, the research has found that the fewer the clusters of differentiation antigen 4 (CD4), the higher the degree of depression in people living with AIDS, and the higher the degrees of self-perceived stress and social stigma. ${ }^{[15]}$ At present, even though AIDS is incurable, highly active antiretroviral therapy can effectively control the disease condition, and the number of survivors is increasing. ${ }^{[16]}$ In Taiwan, the aging of the patient and the multiple complications caused by the disease have resulted in people living with AIDS relying on caregivers. ${ }^{[16]}$

In addition, although most people living with AIDS in Taiwan are men, the number of women living with AIDS is increasing annually. ${ }^{[17]}$ Research has found that women living with AIDS retain their partners or gain new partners after their diagnosis is confirmed; however, they retreat and engage in self-handicapping when pursuing intimacy, which weakens their position in a romantic relationship. ${ }^{[17]}$

When the family members of people living with AIDS in Taiwan learn that their loved ones are infected, they experience negative emotions of shock and shame, and keep the disease a secret to avoid discrimination, thus affecting the relationships between family members. ${ }^{[18]}$ In particular, when parents learn that their children have been diagnosed with HIV, they may feel shame because of their prejudices about AIDS; however, in general, they will see it as their duty to do their best to take care of their children. The provision of this long-term care can affect parents' physical and mental health. ${ }^{[18]}$

People living with AIDS often face multiple dilemmas after diagnosis. In addition to the disease, both the people living with AIDS and their caregivers experience social discrimination caused by the stigma associated with the disease, and this situation often causes different levels of physical, psychological, social, and spiritual problems. Therefore, this study aimed to explore the life experience and stories of people living with AIDS and their caregivers through narrative research that involved one-on-one in-depth interviews, which enabled the respondents to narrate their own stories.

\section{RESEARCH METHODS}

This study adopted the narrative method in qualitative research. Through text, the life experience of the participants is vividly demonstrated and interpretive conclusions 
are drawn. ${ }^{[19]}$

\subsection{Research design}

Narrative research is the life story of an individual or group accounted by an interviewee, and includes autobiographies, oral histories, life stories, case studies, and various themes of other people's life stories. Therefore, when forming the research questions, it is necessary to consider the limitations of the research scope, determine the protagonist of the study, determine the first person and the witness, ensure the story covers both roles, and explore differences between the participant and the researcher. ${ }^{[19]}$ The research questions in this study were formulated based on the research purpose and participants.

This study explored the internal struggles that have occurred through the course of the disease of people living with AIDS and their primary caregivers. Therefore, the purposive sampling approach was adopted. The participants were people living with AIDS and their primary caregivers, as designated by the person living with AIDS. The selection criteria for participants were that they were at least 20 years of age, could describe their experience in Mandarin or Taiwanese, were in acceptable physical condition and expressed their willingness to participate in the study and attend a recorded interview after the content of the study was explained. The selection criterion for primary caregivers was that they must understand the condition of AIDS patients. The exclusion criteria for participants were if the person living with AIDS was unconscious due to an illness such as hepatic encephalopathy, had moderate to severe depression or dementia, was unable to complete the interview due to physical discomfort, or refused being recorded during the interview. The exclusion criteria for caregivers were not knowing the condition of AIDS patients or refusing to be recorded during the interview.

After being reviewed by the institutional review board (IRB) of an AIDS-specific regional teaching hospital in central Taiwan, infectious disease doctors and AIDS case managers in the hospital identified outpatients, inpatients, and caregivers who met the selection criteria. The researcher personally explained the purpose of this study to the participant and inquired about their willingness to be interviewed. After consent forms were obtained from the participants, the interviews commenced. They were conducted in locations such as the outpatient clinic, the discussion room of the nursing station, and the participant's home, according to the wishes of individual participants. Every interview was recorded. During the interview, the questions in the interview guide (see Table 1) were used to guide the participants in narrating the effects of AIDS on their lives.

A total of 16 participants were approached, and 12 were successfully interviewed: six people living with AIDS and six caregivers.

\subsection{Data collection process}

Interviews are one of the primary data collection tools in qualitative research. Researchers must first abandon their experience and preset knowledge and encourage participants to use their voice and words to describe their essential life experiences. ${ }^{[20]}$ Open-ended questions are asked to induce participants to construct their own answers. If the interview focus is ambiguous or the participants provide insufficient content, related questions should be posed, and the interview details can be followed up to clarify and confirm the participants' meaning. Interview atmosphere, mutual trust, and a friendly relationship should be carefully maintained. ${ }^{[19]}$ The direction of a study gradually emerges from reviewing the collected textual data. Through reading and analysis, hypotheses and theories are generated and presented in an interpretive manner and then proved through sufficient justification. ${ }^{[21]}$

The purpose of this study was to explore the life experience of people living with AIDS and their caregivers. In this study, data collection and data analysis were undertaken in Chinese. After data analysis was accomplished, the Chinese manuscripts were given to a professional translator to translate into English, and all the authors then reviewed and agreed on the English manuscript before it submitted to the journal.

The participants were encouraged to describe core events in their life stories, such as people, events, and objects at defining moments. Open-ended questions (see Table 1) were posed to explore the emotions and feelings of the participants. During the interview process, the researcher listened to the participant's verbal responses and recorded their nonverbal responses. Each interview was undertaken by the second author, and she then converted the recordings into verbatim transcripts. If a participant paused or had difficulty in speaking, he or she was given time to think. A recap of the interview content was excerpted and repeated to the participant at the end of each interview. If a participant had emotional moments, he or she was asked if the interview should be paused or continued. After a few minutes to rest and calm down, most participants were able to continue their interview. No participant stopped the interview. 
Table 1. Interview guidelines
People living with AIDS:
Please describe your thoughts after learning that you were diagnosed with AIDS.
What do you think your family (referring to a caregiver) thinks about you?
What changes do you think will occur in your life in the future?
Please talk about how you experienced the disease process. What was your main form of support?
How do you want your family to assist you?
Caregivers:
Please describe your thoughts when you learned that your family member was diagnosed with AIDS.
What do you think he or she (the person living with AIDS) thinks about you?
What changes do you think will occur in your life in the future?
Please talk about how you experienced the disease process. What was your main form of support?
How do you want your family to assist you?

\subsection{Data analysis}

This study used structural narrative analysis to define the subject terminology. ${ }^{[19]}$ The complete form of a structural narrative has six elements: abstract, orientation, complication of essential events, evaluation, result, and coda. ${ }^{[20]}$

The stories were rearranged and insights were explored. The rearranged stories were carefully examined to retain the elements of the narrative content. ${ }^{[14]}$ If the participants spoke in Taiwanese, their emotions and tones were described using terms and interjections or expressions in Taiwanese. The abstract and introduction were analyzed and underlined line by line to confirm the content. The underlined segments, which could be either incomplete or complete but contained essential information, were recoded into a narrative form to retain the original intention of the participant.

Recordings and transcripts were carefully and repeatedly listened to in order to identify the time points of critical events, critical people, and the relationships and responses between the researcher and participant, and to define the narrative history used by the participants. The language used by the participants was analyzed to understand how the participants saw themselves and their environments. ${ }^{[20]}$ The context and cultural contexts in the transcripts were analyzed and the time points of essential events were identified; thus, the participants could elaborate on the most relevant stories. ${ }^{[21]}$

Subsequently, the texts were reoriented to identify the contexts between people, events, time, place, and objects. The data were analyzed to identify whether similarities existed among the aforementioned factors, and similar data were placed in the same categories. Complications in terms of essential events were determined, and the content was reevaluated to identify the representative core concepts and themes, verify the analysis, and compile the results of the stories. From these results, the researcher created a new story and a code.
Trustworthiness was used to evaluate the research rigor of this study. The rigor of this study was examined using persuasiveness, correspondence, coherence, and pragmatic use, as proposed by Riessman. ${ }^{[21]}$ Persuasiveness was addressed by the researcher writing a complete and true rewritten story. Because the participants were from particularly vulnerable groups, for their privacy, the study results were only discussed among the authors. After the discussion, the agreement of data analysis was made to achieve greater correspondence and credibility. For the results of the study, themes were identified from the transcripts and then classified. Finally, a coherent new story was formulated.

During data analysis, the researcher identified clear themes and constructed an HIV-positive protagonist (Paul). A rewritten story that included his caregivers (his sister (Rain), mother (Mary), boyfriend (Flag), and a friend since elementary school (Red) and healthcare professionals was created to demonstrate the research results. The names used for the story were pseudonyms, and the plot of the content was formed from the analysis of the interview results of the 12 participants.

Ethical considerations were adhered to throughout the study. The study was approved by the hospital's institutional review board, and only commenced after written consent forms were obtained from all participants. Before the interview, the research themes, research purpose, and confidentiality of data were explained to the participants. Private and undisturbed interview sites were arranged. During the interviews, none of the 12 participants interrupted the interviews or had to be transferred to a mental health clinic for counseling. After the interviews, the transcripts and demographic information, recording files, and voice recording devices were stored in a locked cabinet. Thus, ethical requirements of informed consent and respect for autonomy, privacy, and confidentiality were fulfilled. 


\section{RESULTS}

The results of this study were the life stories of the 12 participants: six people living with AIDS and six caregivers (seven males and five females). The caregivers comprised girlfriends, family members (i.e., mothers and sisters), samesex partners, or close friends. Table 2 provides the demo- graphic information of the 12 participants. In the rewritten story, quotation marks indicate direct dialog between two people. In this dialog, for example, I1 represents the transcript of the first participant. The original words used by the participant are presented in italics. Words without labels and italicization were added to enhance readability.

Table 2. Demographic information of participants

\begin{tabular}{|c|c|c|c|c|c|c|c|c|c|c|c|c|}
\hline No. & $\begin{array}{l}\text { Inter- } \\
\text { view-1 }\end{array}$ & $\begin{array}{l}\text { Inter- } \\
\text { view-2 }\end{array}$ & $\begin{array}{l}\text { Inter- } \\
\text { view-3 }\end{array}$ & $\begin{array}{l}\text { Inter- } \\
\text { view-4 }\end{array}$ & $\begin{array}{l}\text { Inter- } \\
\text { view-5 }\end{array}$ & $\begin{array}{l}\text { Inter- } \\
\text { view-6 }\end{array}$ & $\begin{array}{l}\text { Inter- } \\
\text { view-7 }\end{array}$ & $\begin{array}{l}\text { Inter- } \\
\text { view-8 }\end{array}$ & $\begin{array}{l}\text { Inter- } \\
\text { view-9 }\end{array}$ & $\begin{array}{l}\text { Inter- } \\
\text { view-10 }\end{array}$ & $\begin{array}{l}\text { Inter- } \\
\text { view-11 }\end{array}$ & $\begin{array}{l}\text { Inter- } \\
\text { view-12 }\end{array}$ \\
\hline Sex & Female & Male & Female & Male & Female & Female & Male & Male & Male & Male & Female & Male \\
\hline Age & 63 & 26 & 60 & 30 & 30 & 33 & 35 & 45 & 35 & 41 & 36 & 64 \\
\hline $\begin{array}{l}\text { HIV } \\
\text { diagnosis }\end{array}$ & $\mathrm{X}$ & $2 \mathrm{yr}$ & $\mathrm{X}$ & $6 \mathrm{yr}$ & $\mathrm{X}$ & $\mathrm{X}$ & $0.5 \mathrm{yr}$ & $\mathrm{X}$ & $5 \mathrm{yr}$ & $5 \mathrm{yr}$ & $\mathrm{X}$ & $4 \mathrm{yr}$ \\
\hline $\begin{array}{l}\text { Trans- } \\
\text { mission } \\
\text { route }\end{array}$ & $\mathrm{X}$ & $\begin{array}{l}\text { Homo- } \\
\text { Sexua- } \\
\text { lity }\end{array}$ & X & $\begin{array}{l}\text { Homo- } \\
\text { sexuality }\end{array}$ & $X$ & $\mathrm{X}$ & $\begin{array}{l}\text { Homo- } \\
\text { sexuality }\end{array}$ & $\mathrm{X}$ & $\begin{array}{l}\text { Hetero- } \\
\text { sexuality }\end{array}$ & $\begin{array}{l}\text { Homo- } \\
\text { sexuality }\end{array}$ & $X$ & $\begin{array}{l}\text { Drug } \\
\text { injection }\end{array}$ \\
\hline $\begin{array}{l}\text { HIV- } \\
\text { infected } \\
\text { individual } \\
\text { /Caregiver }\end{array}$ & $\begin{array}{l}\text { Care- } \\
\text { giver } \\
\text { mother }\end{array}$ & $\begin{array}{l}\text { HIV-inf } \\
\text { ected } \\
\text { Son }\end{array}$ & $\begin{array}{l}\text { Caregiver } \\
\text { Mother }\end{array}$ & $\begin{array}{l}\text { HIV- } \\
\text { infected } \\
\text { Close } \\
\text { friend }\end{array}$ & $\begin{array}{l}\text { Caregiv } \\
\text { er } \\
\text { Close } \\
\text { friend }\end{array}$ & $\begin{array}{l}\text { Care- } \\
\text { giver } \\
\text { Wife }\end{array}$ & $\begin{array}{l}\text { HIV- } \\
\text { infected } \\
\text { Homo- } \\
\text { sexual } \\
\text { partner }\end{array}$ & $\begin{array}{l}\text { Care- } \\
\text { giver } \\
\text { Homo- } \\
\text { sexual } \\
\text { partner }\end{array}$ & $\begin{array}{l}\text { HIV- } \\
\text { infected } \\
\text { Husband }\end{array}$ & $\begin{array}{l}\text { HIV- } \\
\text { infected } \\
\text { Brother }\end{array}$ & $\begin{array}{l}\text { Caregiver } \\
\text { Sister }\end{array}$ & $\begin{array}{l}\text { HIV- } \\
\text { infected }\end{array}$ \\
\hline
\end{tabular}

A structured narrative analytical method was adopted to present and formulate new stories. The elements of the narrative content and the dialog quoted in the story were derived from actual quotes of the participants. A small part of the narrative was written by the researchers to ensure that the story was smooth and logical.

\subsection{Inability to speak to others about AIDS}

The busy emergency room is overflowing with the sounds of constant coughing. The doctor on duty picks up a medical record and slowly walks to a corner. Flag, standing on the side, says hastily, "He has had a fever for more than a month. The Chinese medicine he tried was not effective. In the last week, he has been constantly vomiting and experiencing diarrhea. He can't eat (I3) and has a little abscess in his throat. He even has thrush (I2)."

The doctor responds, "The results of his blood test are quite bad. He has pneumonia, and there are small white spots in his chest x-ray. A particular report indicated a positive result, and the situation is not very good. We must transfer him to the intensive care unit (I3)." The doctor closes the curtain and whispers, "We performed an HIV test for you. It's positive (I10)."

"Yeah, I knew it would be (I2)!'” Paul said coldly. "Doctor, I don't want my family to know about this! They could never accept it (I7)!" The doctor nodded.
After a few days, Paul is transferred to a ward. Paul broke down and said to a case manager, "I feel like I'll die this time. I'm really scared. I'm afraid that I'll never wake up if I fall asleep (I10)!" Recalling discussions with his friends a while ago regarding the death of Chang, a colleague, Paul says, "Even just hearing them say words like HIV or AIDS, I have tangled feelings (I9)!"

The case manager asks, "Did you not let your family know (I5)?" Paul shakes his head and says, "I think there needs to be someone in my life who knows everything about me, but I am afraid that she can't accept it (I10)." The conversation between the two ends when Paul's sister, Rain, enters the ward.

Paul lowers his head and asks, "Little sister, you're not daring to ask about me (I10)?” Paul does not dare look directly at Rain.

"HIV (I10)?" Rain says with a slightly shaky voice. "I saw a 'blood isolation' tag hanging on the bed. I figured that it's not something you can get casually. I wanted to ask you, but then I thought that it's pointless to know all that ... Just don't tell other people (I11)."

\subsection{Isolating oneself from the world}

Paul's elementary school classmate, Red, opens the ward door and says in a slightly unhappy tone, "I saw your post 
on Facebook-'Bye, everyone, farewell!' with a picture of a figure walking toward stairs to the sky. Everyone asked you what happened, and then you directly deactivated your Facebook account ... I thought, this is weird, there must be something wrong (I5)!"

"I have HIV (I5)!'” Paul mumbled. "I am dying, I am running out of time (I5).”

"Did you take protective measures (I5)?” Red asked urgently.

"I couldn't! Sometimes the other person refuses (I5)!’ Paul says slightly emotionally. "I used to wash my clothes with my sister's clothes. Now, it's better that we wash our clothes separately. When she brings food, I also ask her to give me my portion first (II1)."

After Red leaves, Paul gets out of bed and thinks, "I told Red that I have HIV, but she didn't have much of a reaction. Am I overthinking (I10)?” Paul slowly walks to the bathroom and looks at himself in the mirror. He cannot help but mutter, "How come I've become so ugly (IIO)?" Rain follows Paul to the bathroom. Paul suddenly wails hysterically, "I'm shaving! I'm afraid that I might accidentally touch you (I9)!'

Rain says to Paul, "Whenever there are visitors, you act as though everything is well. After they leave, I'm blamed for whatever they do. It's been like this for days. You don't have to yell at me after your friends leave (I11)!" Paul falls silent for a moment before looking at his sister and saying, "I dare not fall asleep because I'm afraid that once I close my eyes, I can never open them again (I11).”

"It's all right. After the drug effect wears off, you'll be fine. You still need some sleep (I11).” Rain comforts Paul, and tears suddenly well up in his eyes.

After a while, Paul falls asleep. Rain feels distressed and ponders, "This is the first time that Paul can fall asleep peacefully in the hospital. How has he been living during this time (I6)?"

\subsection{Promises that cannot be given}

Before dawn, the nurse on the overnight shift enters the ward. Paul asks "Can we stop the injections? I feel very uncomfortable (I2)!" The nurse shakes her head with a smile. After finishing the intravenous drip, Rain holds Paul as he sits on the edge of the bed. Paul starts to talk about his past. "At that time, I left home to work and began to come into contact with society. Only then did I find that I was quite popular, and someone even wanted to be my sugar daddy. I thought to myself, a guy like me, how could someone want to be my sugar daddy? What was that guy thinking (I10)!” They both laugh. After a moment, Paul takes a deep breath and says slowly and with dignity, "Did you know? Actually, I am gay (I2)." Rain opens her eyes wide with shock. "Don't tell mom yet. I am afraid she'll be agitated. I don't think I can tell her about this now. I can't bear the consequences (I2)." Rain suddenly thinks of something their mother once told her. "Once I overheard your brother talking on the phone, and I asked him if that was his girlfriend. He said no, that was a boy on the phone (I3)!"

Paul sorrowfully begins to unburden himself of the pain in his heart. "I know that mom thinks that among her children I am the most competent, and she sets high expectations for me (I2)." He sighs and continues, "I am the big brother at home and I am dignified. I have been called "big brother" since I was a child. I was educated to be independent and rely on myself. Because I am the eldest child, I must set an example for my younger brothers and sisters (I10).” Rain continues to nod.

"When we were little, we were often beaten by dad. I felt I wasn't loved! It was domestic violence (I7)!" Paul said agitatedly. "I hide these things deep in my heart. This is why I do not want to get married and have children (I7)."

"You are the eldest son and the eldest grandson (I9)," Rain says anxiously.

"But I can't tell mom that I am gay. When mom learned about my illness, she was so lost and desperate (I2)." Paul tells Rain with a slightly mocking tone, "I can't just say I like boys; there is no way (I2)! I don't want to get married (I2). Anyway, I can't promise them marriage and children (I4)!" Paul answered helplessly but firmly.

\subsection{Condemnation from others for having AIDS}

After 14 days of treatment and hospitalization, Paul's mother, Mary, is the happiest person to see him discharged from hospital.

"I often think that you are such a great kid, why would you have this disease? I don't know, how can a good child become like this (I1)?" Mary continues, "When you were little, I didn't have much time to be with you. Now that you've grown up and are in this condition, I must take care of you. When you were sick and hospitalized, I even wished I could give you a few years of my life (I1)!"

Mary is busy with housework and says, "When you lived in other places and were pursuing a fruitful life, I agreed with you and said sure, go play if you have money ... but then I thought, is this right or wrong to let you kids be so free (I3)?" Mary sighs, "Did I not do well enough? Why has my child been diagnosed with this disease (I2)? Actually, it's okay now, you are good and do not need my instruction. You are more cautious after getting this disease. Now we can live together; it's a little late but worth it (I3)." 
"Since I'm sick, might as well face it bravely (I3)! I survived such a serious disease, so I must be blessed later in my life (I3)!’ Paul says jokingly.

Mary says to Paul playfully, "You've been born again! Nothing matters now. After rain comes sunshine! I think of it as a test for me (I3)!"

Paul's hospitalization makes Red think deeply. "Lots of tests during his hospitalization required signed consent from the family. Paul is currently single. Signing the consent form indeed presents a dilemma! If his condition is unstable in the future, who should sign it?" Suddenly, a thought flashes into Red's mind, “Anyway, he's not going to get married. The registration of marriage is only a form and a legal relationship. It's just an agreement that lets me make decisions for him in an emergency (I5)!"

With these doubts and predicaments in her mind, Red cannot help but think of the promise they made as children in elementary school.

"I don't think anyone will marry you! When you make it to 30, I'll have to marry you! I have to take care of you (I5)!" Paul had said playfully. Red had told Paul, "If I'm not married in the future and you're not either, we will rent an apartment after retirement. We will live there and take care of each other (I5)."

\subsection{Unknown future}

Late at night, Flag snuggles up beside Paul on the sofa in the living room. "Do you know I used to be handsome? When I worked in the north, I dressed formally and looked like a super star! I was often secretly photographed, especially when I was working (II0)," Paul said proudly.

Recently, Flag has been planning to quit his job and return to the countryside. He asks if Paul would like to join him.

"Are you an idiot? I am sick. I don't even know what will happen to me (I6)!" Paul replies.

Flag responds, "You just have an immune system problem (I6)! I feel that life is too short. If you are not mentally well adjusted, you will never find inner peace. Really! Who is going to help you achieve your inner peace? Of course, the answer is your lover (I6)!" Flag says bashfully. "Actually, it's not that terrible. It is like a chronic disease. You just have to adjust the schedule of your daily life and constantly take medicine. Your life span can still be long, just like an ordinary person (I5)."

Paul looks at Flag with a serious expression. "Is it true that gay people are destined to get this disease (I7)? I think that maybe God is punishing me for being gay (I3)!" Paul continues with the self-deprecation. "When I was little, a blind

Published by Sciedu Press person told me that I have some flaws in my body and I must complete some tasks. So, I asked myself, 'What else can I do (I10)?" Another day, after finishing work as a volunteer in a nursing home, Paul waits for a bus. He sees a clean, tidy, elderly person sitting amongst a group of homeless people on the street, appearing particularly conspicuous.

"Uncle, why are you here in the park (I12)?" Paul asks tentatively.

"One night, I suddenly passed out and was sent to the hospital for some checkups. I was found to be infected with the disease (I12)." The old man pauses and says, "I also did cleaning work but I easily became tired and out of breath. After being diagnosed with the disease, my physical strength suddenly disappeared (I12)!" He appears to be talking about it casually, but Paul sees tears in the old man's eyes.

"Infected?" Paul asked curiously.

"AIDS! I am not afraid to tell people. It's already like this anyway. It doesn't matter if I die! I am afraid that it will be passed on to other people! My friends are afraid to talk with me. They say it is contagious (I12)!" The old man replies.

At this moment, the old man rolls up his trousers and points to his deformed leg. "I jumped from the third and fourth floors three times. I just wanted to die. I fell from the fourth floor and broke my leg in several places, yet I am still alive! Ifeel pain but cannot die (I12)!'”

The older adult's words echo in Paul's mind. He thinks, "Since being diagnosed with the disease, many things have changed. The future is simply unknown. I don't know what the result will be. Let it be, let's wait and see!"

\subsection{Looking for an answer under the shadow}

Most of the people living with AIDS were diagnosed when they were young or experiencing success in their career from this study. Although they were well aware of the reason they contracted the disease, various questions still emerged, and the caregivers began to speculate about possible reasons for the illness after discovering certain facts related to the person living with AIDS. Having AIDS is always difficult for the participants living with AIDS in this study to reveal when faced with their caregiver's questions; however, after a reluctant confession, the participants with AIDS realized that they had overreacted. Also, the caregiver was not as surprised or scared as he or she had imagined. Because of the stigma and discrimination associated with the disease, homosexual participants living with AIDS in this study obtain the courage to survive through the support of a relationship. Nevertheless, this also means that they cannot make a promise to continue the family line. The caregiver participants in the primary family also feel condemnation from others for the 
HIV-infected family member, and often blame themselves and feel guilty. After recovering from severe illness, both the participants living with AIDS and the caregiver have the chance to reflect on their lives.

The current social environment in Taiwan continues to view people living with AIDS negatively. Even after the infected people recover from the immediate serious illness and see the future more positively, AIDS still casts a shadow on the infected people's lives. Therefore, they have no choice but to compromise with the real world.

\section{Discussion}

Thirty-eight years have passed since the discovery of the world's first person living with AIDS in 1981. Due to the rapid advancement of medication, the medical issues associated with having AIDS are not the only problems faced by people living with the disease. AIDS has become a chronic disease as people living with AIDS are gradually aging. ${ }^{[16]}$ Four outcomes of the study are discussed: the dilemma of disclosing a patient's condition, discrimination from stigma, reflections and epiphanies of caregivers, and compromise with the real world. These outcomes wove a rich life narrative between the people living with AIDS and their caregivers.

\subsection{The dilemma of disclosing a patient's condition}

Due to the stigma associated with AIDS, people living with AIDS usually do not easily seek medical treatment. Only when symptoms are severe do they willing undergo testing and accept treatment. ${ }^{[22]}$ The six participants in this study were diagnosed with AIDS when they had complications with infection. People living with AIDS are usually aware of their condition but still experience difficulty in accepting the diagnosis. ${ }^{[13]}$ Some people who are unprepared for the diagnosis may experience psychological breakdown. ${ }^{[22]}$

Among the participants in this study, the four individuals infected through homosexual transmission were conscious of their condition, whereas the other two infected through heterosexual transmission were unprepared. However, unlike the findings of Gesesew et al. ${ }^{[22]}$ and Imazu et al., ${ }^{[13]}$ this study found that some participants had a significantly calm response, which may be what is known as smiling depression, a mild type of depression. ${ }^{[23]}$ Three people living with AIDS in this study had a higher socioeconomic status. When encountering the symptoms of the disease, they smiled and presented positive attitudes; however, this reaction masked the depression caused by the disease. They deliberately exhibited a calm attitude in front of others to save face and maintain their self-esteem.

When learning of a diagnosis, people living with AIDS in 18 this study usually experience a dilemma because they cannot anticipate their loved ones' reactions and they do not know how to explain their condition. An effective social support system can increase the compliance of people living with AIDS in terms of medication use, therefore the disclosure of illness status is a prerequisite for social support. ${ }^{[24]}$ Currently, the public lacks the correct knowledge about AIDS. Most people are generally afraid of and unable to accept people living with AIDS. ${ }^{[7,13]}$ In addition, people living with AIDS are worried that they or their families might be ostracized, so they usually only reveal their illness to family members, intimate partners, or significant others when they are in a critical condition, but not to others.[13,24] In this study, four of the six participants with AIDS were homosexual, two of whom informed their family about their condition, one revealed it to a best friend, and one informed an intimate partner. The two heterosexual participants told their families. None of the six participants disclosed their illness to their colleagues.

With regard to caregivers, Lua et al. ${ }^{[14]}$ found that in the face of the stigma and discrimination induced by the disease, caregivers are often reluctant to inform others. Because of these confidentiality measures, caregivers obtain limited support from other family members, with the relevant information and support being mostly provided by healthcare professionals. ${ }^{[14]}$ The six caregivers in this study learned the status of the person living with AIDS indirectly by noting the frequency of the need for medical treatment or from information leaked during shift handover. After discovering the status of the illness, almost all caregivers were surprised; however, they soon replaced their negative feelings of blame and fear with an encouraging attitude toward the person living with AIDS. To protect the people living with AIDS, the caregivers keep the status of the illness confidential. These results reflected those obtained by Lua et al. ${ }^{[14]}$

\subsection{Discrimination from stigma}

Since the beginning of AIDS epidemic, HIV/AIDS was associated with irresponsible. Furthermore, promiscuity and homosexuality which attaches to a moralizing discourse to biological phenomena. ${ }^{[25]}$ Homosexuality has been recorded in ancient Chinese history. ZiZhi Tongjian (edited by the historian Guang Sima during the Song dynasty) recorded the story of "broken sleeves" (a story describing the homosexual relationship between an emperor and his male imperial concubine), and later this term became a synonym for homosexuality. ${ }^{[25]}$ Males in China have the responsibility of carrying on the family name, and this responsibility is an issue for homosexual people living with AIDS, who are obligated to marry and have a family when they have reached a marriageable age. In the face of pressure from cultural 
norms and social duties, they are charged with the inability to pass on their family genes. ${ }^{[26]}$ They are afraid of the embarrassment and shame they would experience after disclosing their illness and also of the sense of isolation that would result from being rejected by their families. Therefore, most choose to hide their illness. ${ }^{[8]}$ To fulfill their parents' expectations, homosexual people living with AIDS usually choose to marry women in general, lesbians, or heterosexual women. ${ }^{[26]}$

In 2013, for AIDS prevention and control the WHO launched its vision of Zero Infection, Zero Death, and Zero Discrimination. ${ }^{[27]}$ According to a survey conducted by a nongovernmental organization in Taiwan, after people living with AIDS reveal their condition, they feel that family members are indifferent, or when emergencies occur, they have no one to rely on. ${ }^{[27]}$ Some studies have found that the higher the scores of AIDS knowledge for healthcare professionals, ${ }^{[28,29]}$ the more positive their attitudes and behaviors are. If they have received relevant education and training courses during their employment, they are more inclined to take on care work. However, $40.7 \%$ of healthcare professionals are afraid of caring for patients with AIDS, 56.2\% take excessive protection measures, $37.9 \%$ are afraid of touching patients, and $23.2 \%$ are afraid that their loved ones would find out. ${ }^{[29]}$ Moreover, patients who are skilled, educated, and qualified for the job position, other factors such as stigma and employment discrimination in the workplace may obstruct employment opportunity even among highly educated people living with HIV/AIDS. ${ }^{[36]}$ These results indicate that there is still some room for improvement to reach zero discrimination.

People living with AIDS often have a strong sense of selfblame and punishment after infection. In addition, painful treatment or attempts to quit treatment due to the side effects of medication may lead to the desire to give up treatment, or even suicidal thoughts. ${ }^{[30]}$ This study found that people living with AIDS develop a feeling of inferiority after the onset of the illness, fearing that others would discover it. They also fear that they could transmit the virus to their family members and would deliberately isolate themselves from others, fearing that the disease would cause death and result in pain for their loved ones.

Five of the participants in this study were homosexual (four were HIV-infected and one was a caregiver). Three HIVinfected participants indicated that they could not marry and have children due to their sexuality and illness. Therefore, they were unable to promise that they would marry. One person living with AIDS and one caregiver said that they could accept marriage if they had the opportunity. These results were the same as those of Steward et al., ${ }^{[26]}$ which may

Published by Sciedu Press reflect that both studies were undertaken with participants from the same cultural background.

Furthermore, for health care professionals, the protection of patients' privacy should be strengthened during regular shift handovers. The name of the disease can be indicated by codes to avoid caregivers indirectly learning of the diagnosis.

\subsection{Caregiver's reflections and epiphanies}

People living with AIDS and their caregivers must understand their own experiences to find renewed meaning in their life. When close family members learn of the condition of the person living with AIDS, they experience complex emotions, similar to those of a traumatic event. In the face of these destructive and negative emotions, family members will inevitably experience substantial pressure. ${ }^{[14]}$ If the caregiver is a woman, she usually assumes responsibility for looking after the daily life of the person living with AIDS. ${ }^{[14]}$ Also, when parents face their diagnosed children, they feel guilty because they feel they have failed in their duty to nurture their children. ${ }^{[31]}$ Out of love and an unwillingness to let their children experience pain, parents do their best to protect their children and hope to suffer in their place. Also, physical exertion, keeping secrets and the failed realization of their hope for an heir to carry on the family name often cause considerable pressure for parents. ${ }^{[18]}$ Two caregivers in this study were mothers; both felt guilty when they learned of the diagnosis. They felt that they had not taken care of their children since childhood, and they even believed that their children's illness was due to their own unfortunate fate. These guilty feelings place more pressure on the parents. This result is the same as that reported by Lua et al. ${ }^{[14]}$

The medical culture in Taiwan remains centered on the family of origin, therefore same sex partners are not able to actually make medical decisions for their sick partners. To qualify as a health care proxy, young female caregivers can apply for a fake marriage. However, following changes in family and social structures, legal authorization of a partner as a health care proxy is a new possibility. ${ }^{[32]}$ Since 1986 and for more than 30 years, homosexuals in Taiwan have fought for the right to same-sex marriage with the legislative, administrative, and judicial authorities. Additionally, in 2017, same-sex marriage was legalized in Taiwan. ${ }^{[33]}$ In this study, a young female caregiver was unable to make a medical decision for her friend and wished to become a health care proxy using marriage.

\subsection{Compromise with the real world}

In this study, some HIV-infected participants said that after becoming ill, their body became unattractive, which affected their self-confidence. The stigma caused by the disease can 
lead to poor body image in people living with AIDS, and combined with poor social support, this results in poor satisfaction with life. ${ }^{[34]}$

Because AIDS is a high-stress disease, patients require stress relief and health care. The HIV-infected participants in this study expressed that they started to consider adjusting their lifestyles after they became ill. As observed with the participants of this study, after diagnosis and a period of adjustment, a person living with AIDS will begin to consider how to live with the disease. Following treatment and education about the disease, the person living with AIDS will re-examine his or her life, ${ }^{[12]}$ especially to ensure they take their medication every day and thus obtains the benefits of treatment. ${ }^{[13]}$ By understanding the disease, the caregivers were more able to face the disease with a positive attitude. They readjusted their lifestyles to better coordinate with the daily schedule of the people living with AIDS to provide more comprehensive care. However, when caregivers are dealing with HIV-infected family members, they often experience problems such as anxiety about facing death, for which they should seek spiritual support. ${ }^{[10]}$ In addition, people living with AIDS and their caregivers show thousands of unspoken social relations and their daily life of challenges, emotional limitations and interdependency. ${ }^{[35]}$

When the body and mind has adapted, a person living with AIDS still experiences considerable pressure from social discrimination and living in the shadow of disease. Due to the stigma of the disease, following diagnosis people living with AIDS also experience changes in their social relationships with the people closest to them, and confront uncertainties, insecurity, and a fear of the unknown. ${ }^{[7]}$ In addition, the participants in this study mentioned that because the diagnosis was a fact, they should go with the flow and treat life and death with a normal attitude. People living with AIDS have lived in the shadow of disease for a long time and often have physical, psychological, and social problems. Furthermore, they have an uncertain future. Whether it is a person living with AIDS or a caregiver, he or she often fears being ostracized by others and dares not reveal a positive diagnosis.

\section{Conclusion}

The number of people living with AIDS worldwide is rapidly increasing. The considerable advancement of therapeutic medicine has increased the number of survivors annually and has now made AIDS a chronic disease. However, due to the current stigma of the disease, those who are known to be HIV-infected are still only the tip of the iceberg. There are countless people secretly living with AIDS worldwide. Unlike other chronic diseases, caregivers also face the problem of stigma. This study adopted a qualitative, one-on-one, in-depth interview method to guide respondents in expressing their or their family members' psychological journeys after learning of an AIDS diagnosis. Five themes were summarized from the interview transcripts: the inability to speak to others about AIDS, isolating oneself from the world, promises that cannot be given, condemnation from others for AIDS, and having an uncertain future. As well as their own individual struggles, the person living with AIDS and the caregiver have problems that they must face together. They must learn how to survive in a world full of discrimination, shame, and stigma. Learning and understanding about the experiences of both people with AIDS and their caregivers who have already had the face the issues associated with the disease can help other people with AIDS and their caregivers to support each other through the course of the disease.

In the 21 st century, when medical science and technology are advancing, the Internet, newspapers, media, and other more directed education have enabled easy acquisition of AIDS-related knowledge. However, the public still cannot accept AIDS. Governments worldwide are investing significant manpower and resources to cease the rapid spread of the disease. In a short period of 30 years, antiretroviral therapy advancements in medical science and technology have changed HIV treatment to being as simple as a once-a-day pill. However, people living with AIDS and their caregivers have not been able to walk out of the shadow of the disease, as even for those who are willing to reveal their illness, the results do not always turn out well. People living with AIDS and their caregivers can only secretly take care of and encourage each other.

\subsection{Recommendation for future research}

The results of this study can be applied to clinical practice, school education, and future research. In terms of clinical practice, work must still be done to reduce the stigma of the disease. For healthcare professionals, having the correct understanding of AIDS is the primary objective. By improving the acquisition of correct knowledge, the quality of care from healthcare professionals can be improved. This would involve also providing the public with correct disease and health education in a timely manner and gradually eliminating the stigma of AIDS.

In terms of school and in-service education, the public still adopts judgmental attitudes toward homosexuals, thereby stigmatizing AIDS. Therefore, this study recommends adding courses related to AIDS epidemiology as elective courses and required courses to enhance students' and clinical nurses' understanding of such diseases. Through interaction, the nursing students and clinical nurses can acquire a deeper understanding of people living with AIDS 
and their caregivers, achieving the WHO's vision of "zero discrimination."

\subsection{Limitations}

This study had two research limitations. Frist, demographic diversity in the participants was lacking, as all HIV-infected participants were male between the ages of 26 and 49 years. Moreover, most of the participants were homosexuals. Second, none of the people living with AIDS included in this study were women or youths, and the caregivers were mostly women and had positive experiences.

\section{ACKNOWLEDGeMENTS}

This study received funding from the Cheng Ching Hospital, Taiwan. In addition, the authors would like to thank the participants for participating in this study and sharing their life narratives. Finally, the authors also thank their colleagues for their support during the study period.

\section{CONFlicts OF InTEREST Disclosure}

The authors declare that there is no conflict of interest.

\section{REFERENCES}

[1] Joint United Nations Program on AIDS [UNAIDS]. Data Sheet. People living with HIV - All ages. 2021. Available from: https : //aidsinfo.unaids.org

[2] Joint United Nations Program on AIDS [UNAIDS]. Data Sheet. New HIV infections - All ages. 2021. Available from: https: //aidsinfo.unaids.org

[3] Joint United Nations Program on AIDS [UNAIDS]. Data Sheet. HIV Prevalence - Adults (15-49). 2021. Available from: https: //aidsinfo.unaids.org

[4] Joint United Nations Program on AIDS [UNAIDS]. Data Sheet. AIDS-related deaths - All ages. 2021. Available from: https: //aidsinfo.unaids.org

[5] Centers for Disease Control, R.O.C.(Taiwan). Statistics of HIV/AIDS. 2021. Available from: https://www.cdc.gov.tw/Category/Pa ge/rCV9N1rGUz9wNr8lggsh2Q

[6] Grodensky CA, Golin CE, Jones C, et al. "I should know better": The roles of relationships, spirituality, disclosure, stigma, and shame for older women living with HIV seeking support in the South. Journal of the Association of Nurses in AIDS Care. 2015; 26(1): 12-23. PMid:24630627 https : //doi.org/10.1016/j.jana.2014.01 .005

[7] Blake BJ, Taylor GAJ, Sowell RL. Exploring experiences and perceptions of older African American males aging with HIV in the rural Southern United States. American Journal of Men's Health. 2017; 11(2): 221-232. PMid:27550774 https : //doi.org/10.1177/15 57988316662875

[8] Jang N, Bakken S. Relationships between demographic, clinical, and health care provider social support factors and internalized stigma in people living with HIV. Journal of the Associated of Nurses in AIDS Care. 2017; 28(1): 34-44. PMid:27720356 https : //doi.org/10.1016/j.jana.2016.08.009

[9] Setlhare V, Wright A, Couper I. The experiences of people living with AIDS in Gaborone, Botswana: Stigma, its consequences and coping mechanisms. South African Family Practice. 2014; 56(6): 309-313. https://doi.org/10.1080/20786190.2014.975484

[10] Amoateng AY, Kalule-Sabiti I, Oladipo SE. Psycho-social experiences and coping among caregivers of people living with AIDS in the North-West Province of South Africa. South African Journal of Psychology. 2015; 45(1): 130-139. https ://doi.org/10.1177/ 0081246314556566

[11] Omer T, Lovering S, Shomrani MA. The lived experience of living with AIDS in the Western Region of Saudi Arabia. Diver- sity and Equality in Health and Care. 2014; 11: 215-23. https : //doi.org/10.21767/2049-5471.100022

[12] Chavez MFC, Maloles MV, Manzano MaPL. The phenomenology of patients living with HIV: Its implications on their coping mechanism. LPU- Laguna Journal of Arts and Sciences. 2016; 2(3): 85-95.

[13] Imazu Y, Matsuyama N, Takebayashi S, et al. Experiences of patients with AIDS receiving mid- and long-term care in Japan: A qualitative study. International Journal of Nursing Sciences. 2017; 4(2): 99-104. PMid:31406727 https://doi.org/10.1016/j.ijnss. 2017.0 2.004

[14] Lua PL, Mustapha N, Abdullah R, et al. The experiences and challenges in caring for AIDS patients: A qualitative exploration among Muslim family caregivers in Terengganu, Malaysia. ASEAN Journal of Psychiatry. 2014; 15(2): 120-130.

[15] Yeh ML, Hsu ST, Ko WC, et al. Depressive symptoms in people living with HIV: Related factors. The Journal of Nursing. 2012; 59(2): 39-49.

[16] Wei HT, Chuang P, Chen MH. Health promotion for the LGBT midlife and older adults. Journal of the Formosan Medical Association. 2017; 21(2): 203-207.

[17] Lai YY, Feng MC, Cheng LF, et al. Intimate relationships narratives of women living with HIV. The Journal of Nursing. 2010; 57(5): 27-35.

[18] Feng MC, Kao SC, Lu PC, et al. The experience of parents caring for adult children with AIDS. The Journal of Nursing. 2008; 55(1): 24-32.

[19] Duffy M. Narrative inquiry: The method. In: Munhall PL. ed. Nursing research: A qualitative perspective. 4 th ed. Middlesex, NJ: Jones and Bartlett; 2007: 401-421.

[20] Wu CY. On the methodology of narrative research. In: Chi L \& Lin PH, ed. Qualitative research methods and data analysis. 2nd ed. Chiayi, Taiwan: Department of Applied Sociology \& Institute of Sociology; 2003: 145-188.

[21] Riessman CK. Narrative analysis: Qualitative research method. Series 30. Newbury Park: Sage; 1993.

[22] Gesesew HA, Gebremedhin AT, Demissie TD, et al. Significant association between perceived HIV related stigma and late presentation for AIDS care in low and middle-income countries: A systematic review and meta-analysis. PLoS ONE. 2017; 12(3): e0173928. PMid:28358828 https://doi.org/10.1371/journal.pone.0 173928

[23] Christodoulou NG, Christodoulou GN. Management of the psychosocial effects of economic crises. World Psychiatry. 2013; 12: 178. PMid:23737430 https://doi.org/10.1002/wps. 20043 
[24] Elopre L, Westfall AO, Michael JMugavero, et al. Predictors of HIV disclosure in infected persons presenting to establish care. AIDS and Behavior. 2016; 20: 147-154. PMid:25855046 https : //doi.org/10.1007/s10461-015-1060-8

[25] Chang DK, Han ZG. Comprehensive mirror to aid in government, New translation (Five): Han, 20 27. Taipei, Taiwan: San Min Book Co. Ltd; 2017.

[26] Steward WT, Miege P, Choi KH. Charting a moral life: The influence of stigma and filial duties on marital decisions among Chinese men who have sex with men. PLoS ONE. 2013; 8(8): e71778. PMid:23951245 https://doi.org/10.1371/journal.pone.0 071778

[27] Taiwan Lourdes Association. Report on the people living with AIDS life status survey 2019 in Taiwan. Available from: https ://www . lourdes . org.tw/OnePage_List. aspx?tid=297\&id=3799

[28] deBoer H, Andrews M, Cudd S, et al. Where and how does physical therapy fit? Integrating physical therapy into interprofessional HIV care, Disability and Rehabilitation. 2019; 41(15): 17681777. PMid:29529881 https ://doi.org/10.1080/09638288. 2 018.1448469

[29] Wu HC, Ko NY, Shih CC, et al. AIDS: An exploration of the knowledge, attitude, infection risk perceptions, and willingness to care of nurses [in Chinese]. The Journal of Nursing. 2014; 61(5): 43-53.
[30] Dabaghzadeh F, Jabbari F, Khalili H, et al. Associated Factors of Suicidal Thoughts in HIV-Positive Individuals. Iranian Journal of Psychiatry. 2015; 10(3): 185-191.

[31] Xiao YJ, Zhan YF, Hong JJ, et al. The assessment of group support system of families of people living with HIV/AIDS and adaptability [in Chinese]. Journal AIDS Care Quarterly. 2019; 108: 36-45.

[32] Lin FY. A study on durable power of attorney for health care-Focusing on the needs of same-sex couples. 2015.

[33] Justices of the Constitutional Court, J. Y., ROC. Interpretations: J.Y. Interpretation No. 748. Available from: http://www. judicial.g ov.tw/constitutionalcourt/p03_01_1. asp?expno=748

[34] Jain P, Tiwari GK. Body image satisfaction and life satisfaction in AIDS patients. The International Journal of Indian Psychology. 2016; 3(2): 81-90. https : //doi .org/10.25215/0302.010

[35] Matthews GJ. Family Caregivers, AIDS Narratives, and the Semiotics of the Bedside in Colm Tóibín's The Blackwater Lightship. Critique. 2019; 60(3): 289-299. https ://doi .org/10.1080/00111619.2 018.1538100

[36] Özdemir HÖ, Tosun S, Özdemir D, et al. The determinants of employability of people living with HIV/AIDS in Turkey. American Journal of Industrial Medicine. 2020; 63(1): 92-98. PMid:31691331 https://doi.org/10.1002/ajim. 23056 